\title{
Linguagem e ideologia no jornalismo de revistas: os discursos de Veja sobre as crises de 1999 e 2015
}

\section{Language and ideology in magazine journalism: the discourses of Veja on the 1999 and 2015 crisis}

Mayara Luma Assmar Correia Maia Lobato ${ }^{1}$

1 Doutoranda do Programa de Pós-Graduação em Comunicação e Práticas de Consumo da Escola Superior de Propaganda e Marketing (ESPM-SP). Mestre em Comunicação pela Faculdade Cásper Líbero (2012). Jornalista graduada pela Universidade da Amazônia (2009). Professora dos cursos de Comunicação Social do Centro Universitário FIAM-FAAM (São Paulo). E-mail: mayaraluma@gmail.com. 


\section{Resumo}

Este artigo propõe uma análise dos discursos construídos pela revista Veja sobre as crises econômicas enfrentadas pelo Brasil. Para isso, foram selecionadas duas edições: de janeiro de 1999, início do segundo mandato de Fernando Henrique Cardoso, e de março de 2015, primeiro ano da presidente Dilma Rousseff, também reeleita. Como aporte teórico são utilizados autores vinculados aos estudos da linguagem, como Charaudeau, Bakhtin, Baccega, Lippmann e Lonardoni. Ao final, constatou-se que as estratégias discursivas adotadas descortinam os matizes ideológicos da publicação, estabelecidos por meio de um complexo contrato de comunicação com o leitor.

\section{Palavras-chave}

Comunicação, discurso, ideologia, revista Veja, jornalismo. 
This article proposes an analysis of the discourses constructed by Veja magazine on the economic crisis faced by Brazil. Two issues were selected for this study: from January 1999, the beginning of the second term of president Fernando Henrique Cardoso, and March 2015, the first year of president Dilma Rousseff, who was also re-elected. As a theoretical framework, we use authors connected to studies of language, such as Charaudeau, Bakhtin, Baccega, Lippmann and Lonardoni. The analysis shows that the adopted discursive strategies unveil the ideological nuances of the magazine, established through a complex contract of communication with the audience.

\section{Keywords}

Communication, discourse, ideology, Veja magazine, journalism. 
Nossos hábitos de consumo podem dizer muito sobre nós mesmos. Uma observação atenta dos produtos que uma pessoa usa e expõe aos outros pode dar interessantes pistas sobre quem é aquele sujeito. Do mesmo modo, a escolha do consumidor/leitor por essa e não por aquela revista revela a sintonia encontrada - ou não - entre a linha editorial da publicação e seus valores, visões de mundo e preferências. O direcionamento ideológico de uma publicação determina a maneira como os temas serão explorados, o espaço que será dado aos assuntos, as editorias em que serão noticiados e, sobretudo, os modos de agenciamento de seus leitores.

Por vezes confundida com a noção de objetividade, a ideia da transparência da linguagem jornalística, que se pregou por tanto tempo, muitas vezes pelos próprios jornalistas e pelos veículos em que atuavam, é infundada por vários aspectos. Entre eles está a linguagem, sistema do qual este campo obviamente se vale para construir suas notícias - e que o submete a regras próprias. Conforme apontam vários autores, como Baccega (1998; 2007), Bakhtin (1988) e Orlandi (2003), a linguagem não é neutra. Pelo contrário, é uma construção social permeada de ideologia, como as palavras, cujo sentido é sempre ideológico, não estando ligado à sua literalidade, e os discursos circulantes, que revelam relações de poder e juízos de valor - ideias que exploraremos ao longo deste trabalho.

Partindo da relação entre linguagem e ideologia, a proposta deste artigo é analisar os discursos da revista Veja, com foco em duas edições - a primeira de janeiro de 1999 e a segunda de março de 2015. Na primeira, o tema central é a crise econômica; já a segunda explora o tema com destaque, no entanto, colocando-o como parte de uma crise política e de credibilidade do governo. Nossa ideia é examinar de que forma a revista construiu discursos sobre algumas das crises mais recentes enfrentadas pela economia brasileira.

\section{Linguagem, ideologia e discurso: explorando conceitos}

Diariamente, um sem-fim de acontecimentos toma forma mundo afora, mas só conseguimos ter acesso a uma pequena parcela deles, seja por nossas vivências pessoais, seja pelas experiências proporcionadas pela mídia. Os meios de comunicação funcionam como facilitadores de acesso aos acontecimentos, apresentando fatos considerados relevantes para aquela sociedade e gerando enquadramentos para o mundo, ajudando, de certa a forma, a organizá-lo. Na sociedade da informação, essa função ganha ainda mais importância, embora, sabemos, não seja uma atividade neutra.

Para explicar as divergências entre os mais diferentes relatos que encontramos sobre os acontecimentos que nos circundam, Lippmann (1996) se vale da noção de estereótipo - imprescindível para a análise de textos midiáticos. 
Produzir imagens específicas a partir de prévias leituras sobre o mundo é uma atitude normal, já que, como o autor aponta, só temos acesso a uma pequena parte do mundo por meio de nossas experiências - o que demanda o reconhecimento por meio dos relatos de outrem:

Nossas opiniões abarcam inevitavelmente um espaço maior, um lapso de tempo mais longo e um número maior de coisas do que as que podemos observar diretamente. É preciso, portanto, que se formem do que os outros relataram e do que somos capazes de imaginar (LIPPMANN, 1996, p. 149).

Como é impossível "ver todas as coisas frescamente e com detalhes", os estereótipos proporcionam-nos "tipos e generalidades" (LIPPMANN, 1996, p. 155). Eles são passados de forma natural pelas instituições que nos socializam, como a família, a escola, a igreja, os amigos e também a mídia. Com isso, "o processo de estereotipia se apodera da nossa vida mental, (...) os padrões correntes interceptam as informações no trajeto rumo à consciência", como explica Bosi (2003, p. 115-116), e passam a afetar a maneira como vemos o ambiente exterior, já que "na maior parte das vezes, não vemos primeiro para depois definir, mas primeiro definimos para depois vermos" (LIPPMANN, 1996, p. 151).

Os estereótipos que nos são passados ao longo da vida não são construídos ao acaso, muito pelo contrário. Segundo Bakhtin (1988, p. 128), "a fórmula estereotipada adapta-se, em qualquer lugar, ao canal de interação social que Ihe é reservado, refletindo ideologicamente o tipo, a estrutura, os objetivos e a composição social do grupo". Por isso, ao absorver estereótipos, estamos incorporando importantes elementos sociais, históricos e culturais dos grupos dos quais fazemos parte.

A construção de estereótipos só é possível por meio da linguagem, elemento essencial para a constituição do sujeito e da comunidade simbólica, bem como para o trabalho de apreensão da realidade. Vários autores discutem esta ideia, como Baccega $(1998 ;$ 2007) e Bakhtin (1988). Para a primeira, a fala é uma "manifestação concreta da língua, [...] constituindo-se como base do pensamento conceitual". Para esta autora, ainda, o homem só se constitui na interação social que se dá pela linguagem:

Essa interação vai dar-se através da linguagem, sobretudo a verbal; através do aparelho conceptual que ele recebe pelo processo social da educação; através do sistema de valores no qual ele se banha e que é fortemente marcado pela classe social e/ou pelo nível socioeconômico a que pertence (BACCEGA, 2007, p. 11). 
Como se observa a partir das assertivas aqui apresentadas, a linguagem está inserida dentro de contextos sócio-históricos e acaba conduzindo a maneira como entendemos o mundo e nos colocamos nele, confirmando que "não é a atividade mental que organiza a expressão, mas, ao contrário, é a expressão que organiza a atividade mental, que a modela e determina sua orientação" (BAKHTIN, 1988 , p. 114). A linguagem, portanto, acaba funcionando como um instrumento de interpelação ideológica e de determinação do enunciado, em especial a partir da palavra, unidade mínima da comunicação, obviamente, essencial para o estabelecimento de uma língua.

Para Bakhtin (1988), a palavra só adquire significado dentro do campo em que está inserida. Por comportar ideologia, ela se torna, portanto, um signo linguístico, que "vê-se marcado pelo horizonte social de uma época de um grupo social determinado" (BAKHTIN, 1988, p. 43):

(...) a palavra não é somente o signo mais puro, mais indicativo; é também um signo neutro. Cada um dos demais sistemas de signos é específico de algum campo particular da criação ideológica. Cada domínio possui seu próprio material ideológico e formula signos e símbolos que Ihe são específicos e que não são aplicáveis a outros domínios. O signo, então, é criado por uma função ideológica precisa e permanente inseparável dela. A palavra, ao contrário, é neutra em relação a qualquer função ideológica específica. Pode preencher qualquer espécie de função ideológica: estética, científica, moral, religiosa (BAKHTIN, 1988, p. 35).

Baccega (2007) explica essa mesma ideia de Bakhtin de uma maneira simples, porém bastante interessante, ao comparar as palavras e o discurso com músicas e salões de baile, respectivamente. Para ela, as palavras "'dançam conforme a música', tocada no salão de baile onde estão. O salão é o discurso e é aí que elas cristalizam momentaneamente uma de suas máscaras". A autora continua: "as palavras têm vida. Vestem-se de significados. Mascaram-se. Contagiam-se com as outras palavras próximas" (BACCEGA, 2007, p. 6). Ou seja, a palavra só assume significado dentro de um discurso e da teia de sentidos que nele é tecida.

O discurso, por sua vez, é construído socialmente, e as palavras que o compõem não são escolhidas ao acaso. Pelo contrário, ele representa a combinação da palavra com as situações de interação, as condições materiais de sua existência e os lugares ou posições de onde os indivíduos falam. Em resumo, é uma combinação daquilo que é dito com um ambiente ou situação de comunicação: "a situação e os participantes mais imediatos determinam a 
forma e estilo ocasionais da comunicação" (BAKHTIN, 1988, p. 116). Com isso, os discursos são fortemente marcados pelos grupos sociais que dele fazem uso e pelas condições sócio-históricas de sua produção. Portanto, acabam revelando sistemas de valores e relações de poder.

O discurso é sempre ideológico e a todo momento tenta convencer alguém de algo. Por isso, são muitos os sujeitos e organizações que tentam controlá-lo. Essa tensão em torno de quem vai "mandar" nos sentidos das palavras, amplamente examinada nos estudos sobre o discurso, não é à toa. Como se viu mais acima, o homem só se constitui a partir da interação social proporcionada pela linguagem. Nesse sentido, os discursos circulantes (CHARAUDEAU, 2007) assumem papel importante na constituição da consciência dos sujeitos e na maneira como eles interpretarão o mundo à sua volta: "a consciência só se torna consciência quando se impregna de conteúdo ideológico (semiótico) e, consequentemente, somente no processo de interação social" (BAKHTIN, 1988, p. 32). A partir dessas ideias, é possível entender que não haveria consciência individual, apenas social.

Embora o discurso tenha influência significativa na constituição das consciências, não é possível pensar que o sujeito é passivo diante do processo de apreensão dos valores, de modos de ver si mesmo e os outros. O que acontece é uma reelaboração da consciência social: as ideias apreendidas do ambiente externo são combinadas, ratificadas, retificadas e podem até levar à recriação de valores sociais. Portanto, não há como reduzir a importância da atividade mental:

(...) consideramos que aprender a falar significa não apenas aprender a utilizar palavras que a sociedade nos entrega prontas, mas (deveria significar também) aprender a produzi-las. E aprender a produzi-las significa ter uma visão crítica da realidade em que se está inserido e, desse modo, participar do movimento rumo à construção de novas variáveis históricas (BACCEGA, 2007, p. 44).

\section{Os discursos nas - e das - mídias}

Embora exista, como tratávamos mais acima, uma tensão constante para controlar os discursos que circulam em uma sociedade, o mais comum é que esse poder se concentre na classe dominante, que se apropria da linguagem para cristalizar seus valores, ideologias e visões de mundo. Para conseguir isso, a classe em questão costuma valer-se também da mídia que, conforme afirma Lonardoni (2006, p. 113), "de instigadora e veiculadora de verdades passou a reforçar os sistemas econômicos e políticos a que se atrelou". Esse aspecto adquire especial importância na análise aqui proposta, pois a "mídia, dados os mecanismos que a sustentam e reforçam sua presença e sua atuação no dia-a-dia das pessoas, já 
impregnou todos os poros e todas as células da linguagem como atividade social" (LONARDONI, 2006, p. 114).

Trabalhando as ideias de Ignácio Ramonet, editor do Le Monde Diplomatique, Lonardoni concorda que hoje os dois principais poderes são o econômico e o midiático, que estabeleceram uma relação bastante sólida. Quanto ao poder político, só viria em terceiro lugar (LONARDONI, 2006, p. 114). Sem dúvidas, ponderando tal ideia, notamos que a mídia desempenha na atualidade um importante papel, pois contribui para a formação e socialização de uma parcela significativa da população, que costuma acreditar, também, no viés informativo e pretensamente neutro dos discursos produzidos nos meios de comunicação. Para a autora:

(...) apesar de os veículos midiáticos serem responsáveis pela transmissão de fatos e eventos da sociedade a uma gama enorme da população, esses mesmos veículos, além de informar, acabam "formando" uma certa opinião do público a respeito dos fatos e eventos que veiculam. Isto, tendo em vista que, ao descrever, selecionar, organizar e editorar os fatos a serem transmitidos, e ao definir a maneira como esses fatos são levados a público, muito da visão de mundo, dos interesses e da ideologia da instituição são permeados no discurso dito informativo (LONARDONI, 2006. p. 127).

Os discursos que tomam forma na imprensa - e isso é especialmente trabalhado nas teorias do jornalismo - estão sujeitos às mais diversas influências, "são construídos com base no contexto social e histórico de seus enunciadores, e por isso trazem toda a carga conceitual e ideológica de quem os produz". A isso somam-se ainda "os aspectos ideológicos relativos a quem essa instituição está servindo" (LONARDONI, 2006, p. 127). Esses fatores refletem-se na imprensa das mais diferentes formas: pelos sujeitos a quem se escolhe dar voz em cada matéria, pelas palavras que se escolhe usar, pelo destaque dado a cada assunto, as imagens que ilustram a notícia etc.:

Assim, não podemos crer na existência de objetividade e imparcialidade nos veículos midiáticos. De modo semelhante, não podemos nos prender ao discurso de um veículo apenas, pois só com um conjunto de discursos sobre um mesmo fato poderemos perder a ingenuidade diante dos textos midiáticos (LONARDONI, 2006, p. 127).

Todos esses aspectos confirmam a ideia de Bakhtin (1988, p. 40) de que "as palavras são tecidas a partir de uma multidão de fios ideológicos" e assumem seus 
sentidos dentro de discursos que acabam, por isso, não apenas refletindo, mas também refratando a realidade, já que a simples reprodução nunca é possível. Como afirma Baccega (2007, p. 22): "é da natureza da palavra, ao mesmo tempo em que reflete, refratar, desviar - pouco ou muito - o 'sentido' da realidade". A mesma ideia é trabalhada por Charaudeau (2007):

Se são um espelho, as mídias não são mais do que um espelho deformante, ou mais ainda, são vários espelhos deformantes ao mesmo tempo, daqueles que se encontram nos parques de diversões e que, mesmo deformando, mostram, cada um à sua maneira, um fragmento amplificado, simplificado, estereotipado do mundo (CHARAUDEAU, 2007, p. 20).

Assim, enxergamos a atividade midiática como um sistema de produção e reprodução da atividade discursiva e da consequente transmissão de valores, visões de mundo, estereótipos e conteúdos ideológicos que domesticam a realidade visível e derivam de seus sujeitos interlocutores. O foco de nossa análise subsequente está na revista Veja, em duas edições que exploram, com destaque, os problemas econômicos enfrentados pelo Brasil nos últimos anos. Examinar-se-á a maneira como a revista noticiou o comportamento de Fernando Henrique Cardoso e Dilma Rousseff diante dos problemas financeiros do país.

\section{Os discursos de Veja sobre as crises de 1999 e 2015}

A escolha do objeto de estudo deste trabalho não foi feita de forma aleatória. Além das questões ideológicas que buscaremos desvendar ao longo das próximas páginas, alguns importantes números envolvem a revista Veja - que mantém, já há algum tempo, o posto de uma das mais importantes publicações informativas do mundo. Semanalmente, a revista passa de um milhão de exemplares e chega a atingir 12 milhões de pessoas em todas as suas plataformas - além da versão impressa, a publicação conta com versão digital, o portal Veja.com, o aplicativo para celular Veja Notícias e mantém uma das trinta contas mais populares do Twitter.

A história de Veja começa em 1968, quando foi lançada pela editora Abril, tendo o jornalista Mino Carta à frente, como diretor de redação. Os primeiros anos foram difíceis, pois o brasileiro estava acostumado a revistas ilustradas ou a publicações centradas em temáticas específicas, como economia e política, e não a revistas informativas, como Veja, que se inspirava na norte-americana Time (LIMA, 2014, p. 138-139). Nos primeiros anos, a revista acumulou dívidas e, para saná-las, a família Civita, à frente da Abril, decidiu tentar um empréstimo com a 
Caixa Econômica Federal, em 1975. A partir deste momento, a história de Veja e sua postura política-ideológica começaram a mudar.

Com Mino Carta no comando, nos primeiros anos, Veja foi uma revista questionadora e de oposição à ditadura militar. No entanto, para conseguir o empréstimo citado acima, o governo ditatorial exigiu a saída do diretor de redação, que primeiro foi obrigado a tirar férias e, depois de desentendimentos com os Civita, acabou deixando a editora. Essa história é contada pelo próprio Mino Carta em algumas entrevistas e faz parte, também, das memórias da professora e pesquisadora Maria Aparecida Baccega². A partir de então, segundo a professora, a revista foi assumindo a postura ideológica que mantém até hoje, mais conservadora e ligada a partidos políticos de direita.

Naturalmente, os discursos de Veja não são - e jamais poderiam ser transparentes, o que estimula nosso exercício de análise e de busca pelos sentidos aventados a respeito das diferentes crises econômicas e institucionais vividas pelo Brasil na história recente. Assim, buscamos examinar os discursos das mídias para além de sua materialidade - o texto final -, encontrando diferentes modos de dizer e sentidos a respeito dos fatos narrados. Como diz Eni Orlandi:

Os dizeres não são [...] apenas mensagens a serem decodificadas. São efeitos de sentido que são produzidos em condições determinadas e que estão de alguma forma presentes no modo como se diz, deixando vestígios que o analista do discurso tem de apreender. [...] Esses sentidos têm a ver com o que é dito ali, mas também em outros lugares, assim como com o que não é dito, e com o que poderia ser dito e não foi. Desse modo, as margens do dizer, do texto, também fazem parte dele (ORLANDI, 2003, p. 30).

Ao apresentar esses aspectos históricos ligados ao objeto de estudo, justifica-se, também, o motivo da escolha das duas edições. A primeira data de 20 de janeiro de 1999 e traz uma longa reportagem de capa, com 16 páginas, sobre a primeira grande crise enfrentada pelo Real, uma moeda ainda jovem naquele período, com Fernando Henrique Cardoso (PSDB) como presidente do País. Já na segunda, de 18 de março de 2015, a reportagem de capa aborda os problemas econômicos enfrentados pelo Brasil, comandado por Dilma Rousseff (PT), em meio a várias outras questões que compõem na revista um cenário crítico em termos políticos, econômicos e sociais.

20 caso foi relembrado por Baccega durante uma aula no Programa de Pós-Graduação em Comunicação da ESPM, em São Paulo, em junho de 2015. 
Entre as semelhanças das duas edições, aponta-se que ambas foram publicadas no período de início do segundo mandato de cada um dos dois presidentes. Em ambos casos, as edições contêm avaliações do período anterior e exibem previsões/expectativas sobre como serão os próximos quatro anos de governo. Constata-se ainda, em ambos, uma tentativa de diminuir o Brasil em termos econômicos, independentemente do partido político ou do presidente no poder. Observa-se uma manutenção da antiga noção de país de "terceiro mundo", embora a revista não use o termo e prefira, inclusive, chamá-lo de "país emergente" na edição de 1999.

Como exemplo, podemos tomar na edição de 1999 os trechos em que o Brasil é comparado a países como Rússia, México e Tailândia, que apresentariam problemas semelhantes aos nacionais. Mesmo assim, para a revista, essas nações poderiam nos servir de exemplo, como no quadro da página 37 sobre as "lições de fora". O mesmo se observa na mesma página, quando se diz que o Brasil não teve condições de perceber um buraco que já estava cavado há algum tempo e que o país acabou sendo apanhado "por um maremoto imponderável (...) amarrado numa âncora só" (ALCÂNTARA, 1999, p. 37).

Já na edição de 2015, não se usam os termos "economia" ou "país emergente" e as comparações não são feitas com um grupo específico de nações. O que se valoriza são os rankings, como os apresentados nas páginas 50 e 51, que tratam de crescimento do Produto Interno Bruto (PIB), inflação e taxa básica de juros. Com isso, o objetivo é mostrar, valendo-se de números, como o Brasil estaria mal colocado em diversos quesitos, quando comparado a outros países. Ainda na tentativa de desvalorizar o Brasil, a crise econômica mundial é diminuída, já que supostamente "ficou para trás há algum tempo e a grande maioria dos países está em franca recuperação" (GUANDALINI, 2015, p. 49).

Na sequência, uma comparação é feita com a Rússia, um dos países que também aparece como semelhante ao Brasil na edição de 1999: "entre as principais economias do planeta, apenas Rússia possui indicadores tão negativos quanto os brasileiros, em uma combinação venenosa de recessão, inflação nas alturas e juros nas estratosferas" (GUANDALINI, 2015, p. 49, grifos nossos).

Pelos próprios números apresentados, constata-se que a situação dos dois países na época da publicação não era a mesma. Por exemplo, a inflação na Rússia chegou a $15 \%$ no período analisado, enquanto a do Brasil não passou de 8\%; a estimativa para o PIB em 2015 divulgada na edição - e revisada nos meses seguintes - era de que o do Brasil recuaria 0,7\%, já o da Rússia, 3,5\% (informações dos gráficos das páginas 50 e 51). A revista vale-se, assim, de discursos comparativos para conduzir a interpretação do leitor, comprovando o 
que Baccega (2007, p. 32) afirma sobre a palavra, que sempre "procura persuadir, convencer (em maior ou menor grau)", pois "é na língua que a ideologia se materializa" (ORLANDI, 2003, p. 38).

O que se observa é que o discurso de menosprezar economicamente o Brasil se repete de diferentes maneiras nas duas edições analisadas, embora exista um intervalo considerável de tempo entre elas. Pode-se, portanto, considerar que há um processo parafrástico em Veja, que varia apenas na forma de dizer uma mesma ideia já sedimentada. Sobre isso, Orlandi explica:

Os processos parafrásticos são aqueles pelos quais em todo dizer há sempre algo que se mantém, isto é, o dizível, a memória. A paráfrase representa assim o retorno aos mesmos espaços do dizer. Produzem-se diferentes formulações do mesmo dizer sedimentado. A paráfrase está do lado da estabilização (ORLANDI, 2003, p. 36).

Apresentadas algumas semelhanças entre as duas edições, passemos às diferenças. A primeira que chama atenção é a capa. Em 1994, ela é estampada com um barquinho, feito com uma nota de 1 real, que está prestes a ser engolido por um redemoinho, e o único texto é a frase: "manobra correta ou desastre à vista?". Já a capa de 2015 é emblemática: traz uma caricatura da presidente Dilma Rousseff com os olhos vendados pela bandeira do Brasil. Pode-se interpretar que existe a intenção, na segunda edição, de culpabilizar a presidente da República por todos os problemas enfrentados pelo Brasil, inclusive o econômico. Diferentemente, a edição de 1994 não explora na capa a imagem do presidente e concentra-se nos aspectos econômicos.

Outra interpretação revela-se ao longo da leitura da matéria de capa: a insinuação de que a presidente governaria com os olhos vendados por fazer questão de não ver coisa alguma. Dilma Rousseff não se importaria, não daria o valor que a revista julga que deveria às manifestações populares, à dimensão da crise econômica ou à perda de aliados. Essa ideia é trabalhada com clareza no seguinte trecho:

No labirinto em que se encontra, a presidente parece paralisada, relatam aliados, vítima de sua teimosia, da falta de confiança mesmo em assessores mais próximos e da dificuldade em lidar com situações de crise. Mas, a depender do recado das ruas, manter os olhos fechados para a realidade não será mais uma opção para ela (BARROS; PEREIRA, 2015, p. 45). 
No mesmo trecho, observamos fortes críticas à presidente. Como as crises política e econômica que o Brasil enfrenta são associadas pela revista diretamente a Dilma, esta acaba por ser o assunto central da edição, em trechos como o seguinte: "Seria improvável ouvir uma autocrítica presidencial, em que, sinceramente, apontasse os equívocos em série de seu primeiro mandato" (GUANDALINI, 2015, p. 49). Há uma crítica não só ao governo, mas à postura de Dilma, retratada como alguém arrogante. Observa-se tal construção de sentido no quadro entre as páginas 50 e 51, cujo título é "Sem autocrítica".

Outro ponto que chama atenção são as comparações constantes com os anos anteriores à entrada de Dilma na presidência, chamados por Veja de "Pré-Dilma", período compreendido até o fim de 2010, representando, portanto, o governo Lula, também do Partido dos Trabalhadores. São traçadas comparações com o governo atual, gerando mecanismos para atacá-lo a partir de referenciais passados. Alguns trechos contribuem de forma significativa para a construção desse discurso, como "o buraco na economia, na verdade, foi cavado pelo governo, laboriosamente, nos últimos cinco anos" (GUANDALINI, 2015, p. 49), "o país desperdiçou os anos de bonança" (GUANDALINI, 2015, p. 49) e "em termos técnicos, a renda brasileira havia crescido acima dos ganhos de produtividade, desequilíbrio aprofundado pelos gastos e incentivos do governo" (GUANDALINI, 2015, p. 52).

A edição de 1999 possui traços ideológicos igualmente bem marcados. Enquanto, na edição mais recente, a má gestão do PT é culpada pelos problemas enfrentados no Brasil, nessa edição o então presidente Fernando Henrique Cardoso sofre com questões que o Brasil enfrenta há tempos sem solução, como nos trechos: "se não enxugar seus déficits será um país inviável. O problema tem ramificações sociais e políticas graves cuja resolução desafia os governantes há décadas" (ALCÂNTARA, 1999, p. 33, grifos nossos) e "enquanto gastar mais do que arrecada, o Brasil será um país vulnerável seja qual for sua política cambial" (ALCÂNTARA, 1999, p. 34). A revista aponta claramente que o problema não está na política cambial de FHC, configurando-se, na verdade, como um problema histórico da economia brasileira.

Implantado cerca de cinco anos antes da edição analisada, o Plano Real enfrentava problemas pela primeira vez ao fim da década de 1990 e havia gerado um medo grande de que, com seu fracasso, o Brasil voltaria para o cenário das décadas de 1980 e início de 1990 - um "passado caótico de estagnação econômica, inflação crônica e nenhuma importância no cenário mundial", nas palavras da própria revista (ALCÂNTARA, 1999, p. 35). O segundo mandato era, ainda, uma novidade para os brasileiros, já que a lei da reeleição tinha sido aprovada havia pouco tempo. 
Nas duas edições, o Plano Real é apresentado como a salvação da economia brasileira, o que se observa, por exemplo, neste trecho que se refere aos governos do PT: "fechou os olhos para o aumento da inflação, promoveu uma farra de gastos públicos com benefícios e subsídios e solapou os fundamentos construídos, com muito esforço, desde a implantação do Real" (GUANDALINI, 2015, p. 49). Na edição de 1999, "o país, que sumiu do mapa econômico nos anos 80, reapareceu rapidamente como a grande aposta financeira da América Latina". Apresenta-se desse modo a justificativa para a revista criticar quem critica o Plano Real. $O$ seguinte trecho é emblemático:

Do empresário da Fiesp que sofre com os juros altos ao operário que a Ford demitiu, todos atualmente apontam a rigidez cambial e monetária dos últimos anos como a responsável por todo o padecimento do Brasil. Esquecem-se assim os ganhos do Plano Real. O país sofreu a doença da inflação alta durante pelo menos quatro décadas. Em 1994, ela chegou a 953\%. Em 1998, foi quase nula. Distribui-se renda com isso. Segundo o Instituto de Pesquisa Econômica Aplicada, Ipea, o fim da inflação colocou uma renda extra de 7 bilhões de reais ao ano no bolso dos mais pobres (ALCÂNTARA, 1999, p. 37).

Para a revista, o Real, implantado por FHC, foi importante para melhorar as condições de vida no Brasil e beneficiar, principalmente, os mais pobres. $O$ tom difere da edição de 2015, na qual o Brasil é apresentado como "artificialmente mais rico. 0 poder de compra do país havia subido graças à valorização dos produtos exportados e também por causa dos incentivos ao consumo dados pelo governo" (GUANDALINI, 2015, p. 52). Esses fragmentos demonstram que as escolhas das palavras e dos recursos textuais por Veja não são aleatórias. Conforme alerta Lonardoni:

[...] o produtor de um discurso, em especial o midiático, vale-se, além da construção dos enunciados, dos aspectos discursivos e ideológicos de que lança mão e dos mecanismos disponíveis na língua, na sintaxe, na diagramação dos textos etc., para construir discursos ideologicamente marcados. Nesse sentido, nenhuma escolha é meramente casual (LONARDONI, 2006, p. 120).

A forma como a revista apresenta a figura dos dois presidentes nas edições analisadas também merece destaque. Na edição de 1999, chama atenção a matéria cujo título é "Ele está abatido". Já em 2015, o destaque fica para o texto intitulado "E o governo mal começou...". Na primeira edição, é feito um paralelo 
entre Fernando Henrique e Juscelino Kubitschek, presidente entre 1956 e 1961, cujo governo foi marcado por um grande impulso à industrialização do país e ao crescimento econômico. Para a revista, JK, assim como Fernando Henrique, "era uma figura à vontade, sorridente, cordial e exuberante em todos os sentidos".

Já Dilma é comparada a Fernando Collor de Mello, presidente que sofreu impeachment em 1992 depois de vários escândalos de corrupção. Ela é caracterizada como uma pessoa teimosa e que insiste nos mesmos erros, o que se observa no seguinte trecho: "[...] Lula receitou a Dilma o passo a passo desse 'reset' político-administrativo. A presidente apenas ouviu' (BARROS; PEREIRA, 2014 , p. 44, grifos nossos). Além disso, a presidente é mostrada pela revista como indecisa, desconfiada de sua própria equipe - o que acaba por comprometer sua governabilidade - e até insegura:

Os acontecimentos do dia 15 terão importância decisiva para os rumos políticos do Brasil. A partir do recado das ruas, governo e oposição acertarão suas posições e escolherão as armas com que vão lutar. Dilma Rousseff hesita em escolher as suas. No labirinto em que se encontra, a presidente parece paralisada, relatam aliados, vítima de sua teimosia, da falta de confiança mesmo em assessores mais próximos e da dificuldade em lidar com situações de crise (BARROS; PEREIRA, 2015, p. 45).

\section{Considerações finais}

Ao longo deste percurso, verificamos que um mesmo assunto, neste caso a crise econômica e política, foi trabalhado de maneiras distintas por Veja. Confirmamos, assim, nossa hipótese inicial: embora a publicação se inscreva em um discurso de transparência, construído e partilhado pelo campo do jornalismo ao longo da História, suas narrativas são povoadas por uma série de dispositivos ideológicos que guiam o pacto de comunicação estabelecido com seus leitores, definindo seus modelos de agenciamento.

Entende-se que, por meio das estratégias discursivas adotadas, leitor e revista estabelecem uma espécie de contrato de via de mão dupla, como diria Patrick Charaudeau (2007), assumindo um determinado modo de enxergar, interpretar e se relacionar com o mundo - em nosso caso, com os fenômenos transcorrentes nos campos da economia e da política no Brasil. Na mesma linha, Lonardoni (2006, p. 121) reforça este aspecto ao afirmar que "a revista precisa jogar com o mandato do leitor que recebeu de seu público", inserindo-o em um universo discursivo condizente com os elementos desse pacto. Façamos menção, pois, às palavras da mesma autora, também sobre Veja: 
[...] os leitores de Veja sabem do posicionamento político-ideológico da revista e querem saber sua opinião. [...] O leitor conhece o discurso da revista e os efeitos de sentido por ele produzidos nos destinatários e busca exatamente isso nas edições semanais (LONARDONI, 2006, p. 121).

Conforme falamos ao início deste texto, o ato de consumir material de determinados veículos de comunicação evidencia uma relação de consumo, interlocução ideológica e permanente busca por identificação. Nessa relação de mão dupla entre a imprensa e seus leitores, Veja representa um caso de destaque, emblemático, no mercado de revistas brasileiro: alimenta, de forma contínua, os debates da esfera pública do País e lidera em seu segmento. Nosso objetivo, neste texto, foi descortinar tal relação a partir dos recursos discursivos e dos matizes ideológicos transmitidos em suas reportagens sobre a crise - tema que permanece em voga em 2015 e que continuará evocando novos tratamentos e, subsequentemente, novos olhares a partir dos discursos da publicação. 


\section{Referências}

ALCÂNTARA, E. "O Brasil piscou". Revista Veja, ed. 1581, ano 32, no 3, janeiro de 1999.

BACCEGA, M. A. Palavra e discurso: história e literatura. São Paulo: Ática, 2007.

BACCEGA, M. A. "O estereótipo e as diversidades". Revista Comunicação \& Educação. São Paulo. n. 13, set.-dez. 1998.

BAKHTIN, M. Marxismo e filosofia da linguagem. São Paulo: Hucitec, 1988.

BARROS, M.; PEREIRA, D. "E o governo mal começou...". Revista Veja, ed. 2417, ano 48, n. 11, março de 2015.

BOSI, E. O tempo vivo da memória: ensaios de psicologia social. São Paulo: Ateliê Editorial, 2003.

ChARAUDEAU, P. Discurso das mídias. São Paulo: Contexto, 2007.

FILHO, E. "Ele está abatido". Revista Veja, ed. 1581, ano 32, n. 3, janeiro de 1999.

LIMA, S. L. L. Comunicação e época. São Paulo: Plêiade, 2014.

LIPPMANN, W. "Estereótipos". In: STEINBERG, C. (org.). Meios de Comunicação de Massa. São Paulo: Cultrix, 1996.

LONARDONI, M. "O discurso da ascensão, auge e queda de Antonio Palocci, na ótica das capas de Veja". In: NAVARRO, P. (org.). Estudos do texto e do discurso: mapeando conceitos e métodos. São Carlos: Claraluz, 2006.

ORLANDI, E. P. Análise de discurso: princípios e procedimentos. $5^{a}$ ed. Campinas: Pontes, 2003.

SCHAFF, A. "Linguagem, conhecimento e cultura". In: Linguagem e conhecimento. Coimbra: Almedina, 1971.

SCHAFF, A. "Lenguaje y acción humana". In: Ensayos sobre filosofía del lenguaje. Barcelona: Editorial Ariel, 1978. 
GUANDALINI, G. "Como o Brasil foi pro buraco". Revista Veja, ed. 2417, ano 48, no 11 , março de 2015.

submetido em: 22 nov. 2015 | aprovado em: 04 dez. 2015 